\title{
Adherence to Physical Activity in an Unsupervised Setting: The Case of Lapse and Return to Practice in a Brazilian Fitness Center
}

\author{
By Sandro Sperandei ${ }^{*}$, Marcelo Carvalho Vieira ${ }^{\dagger} \&$ Arianne C. Reis ${ }^{*}$
}

This study aims to evaluate adherence, dropout, lapse and return rates of members of a fitness center in the city of Rio de Janeiro, Brazil, and the potential explanatory variables for these phenomena. The study was exploratory and observational, using a retrospective longitudinal frame of reference. The records of 5242 individuals, members of the fitness center between Jan-2005 and Jun-2014, were monitored for 12 months after cancellation of membership or until re-enrolment, whichever occurred first. A Cox proportional hazard regression model was adjusted to identify variables associated with higher probability of returning to activities. The general survival curve shows that $38 \%$ of members who drop out will return to activities within 12 months. Of those who return, more than half return within the first month. The regression model showed that age, previous level of physical activity and length of membership before dropout are related to the probability of returning earlier to activities after an interruption. Combined, those variables represent an important difference between individuals with the best and worse combination of significant variables. Our results can assist in the identification of high risk individuals and therefore help in the development of strategies to prevent abandonment of physical activity and to increase return after interruption.

Keywords: Exercise, Chronic Disease, Health Clubs, Survival Analysis.

\section{Introduction}

The most recent report by the International Health, Racquet and Sportsclub Association (International Health Racquet and Sportsclub Association 2018) confirms that Brazil presents the second highest number of health clubs and fitness centers (HCFC) per capita in the world (34,000 HCFCs), sitting only behind the United States of America with about 38,500 HCFCs. The report indicates that more than 9 million Brazilians belong to private and public HCFCs. Despite the impressive numbers, the same report suggests that the retention rate in these facilities is less than 4\% (International Health Racquet and Sportsclub Association 2018), a worrying statistic given that it is well established that only continued physical activity (PA) practice provides the desired physiological and psychological benefits (Biddle and Mutrie 2007, Kubo et al. 2010). In fact, individuals who train for a very short period of time

\footnotetext{
*Post-Doctoral Research Fellow, Institute of Scientific and Technological Communication \& Information in Health, Oswaldo Cruz Foundation (FIOCRUZ), Brazil.

${ }^{\dagger}$ Physical Education Teacher, Cardiac Rehabilitation Program, Center for Cardiology and Exercise, State Institute of Cardiology Aloysio de Castro, Brazil.

${ }^{\star}$ Director of Academic Program Master of Health Science and Master of Public Health School of Science and Health, Western Sydney University, Australia.
} 
may not even reach the desired physiological adaptations, which disappear wholly or partly after discontinuation (Kubo et al. 2010). For this reason, adherence, retention and dropout rates in PA programs have been increasingly researched internationally (Cañamero et al. 2019, Clavel San Emeterio et al. 2019, Hooker et al. 2016, Kinnafick et al. 2014, Masuki et al. 2015, Teychenne et al. 2015, Viljoen and Christie 2015).

Progress has been made in understanding the motivational factors associated with adoption of PA practice generally (Courneya et al. 2012, Jones et al. 2005, Pridgeon and Grogan 2012, Smith and Biddle 1999), but much remains to be learned about the factors underpinning consistent and long-term adherence to PA (Kinnafick et al. 2014, Viljoen and Christie 2015). It is well established in the literature that personal factors play a role in the adoption and maintenance of recommended levels of PA (Hooker et al. 2016, Jones et al. 2005, Vlachopoulos and Neikou 2007). For instance, research suggests that PA rates decrease with age and differ across gender, social status and educational attainment - with women, low socio-economic status individuals and individuals with less formal education tending to face more constraints to participation (McNeill et al. 2006, Mullen and Whaley 2010, Trost et al. 2002). Social and environmental factors also are important contributors to PA adoption and adherence (Titze et al. 2005, Vieira et al. 2013), with research suggesting that, for instance, women favor group exercise programs because of the social support system developed in these settings (Hanlon et al. 2014, Viljoen and Christie 2015).

However, despite the growing popularity of HCFC worldwide, and in Brazil in particular, these spaces have not received a great deal of attention from researchers investigating adherence, retention and dropout rates in PA programs, with most efforts in this field being concentrated on supervised interventions, randomized controlled trials, and established group exercise programs outside HCFC settings (Berry et al. 2018, Kuehl et al. 2016, Lorenz et al. 2015). Alternatively, some research has looked at these rates within HCFC settings but from a marketing perspective, establishing satisfaction levels and intention to repurchase as some of the main variables to understand PA adherence as consumer behavior (Cañamero et al. 2019, Ferrand et al. 2010, Gonçalves et al. 2016, Hurley 2004). While this body of work has provided invaluable insights into external and internal factors impacting on individual's initiation, adherence and long-term maintenance of PA practice, still very little is known about dropout, lapse and return patterns and its implications on adherence to exercise programs in the unsupervised setting of a HCFC (Clavel San Emeterio et al. 2019, Costa et al. 2009, Garay et al. 2014).

Recent research by the authors involving a sample of 5240 members of a fitness center in Brazil found that the timeframe in which engagement with PA takes place is an important factor when considering adherence to an exercise program (Sperandei et al. 2016). For instance, the study found that even though weight loss was the most prevalent motivation to start the PA program, it was also significantly related to presenting a greater probability of an early drop out. This result suggests that identifying motivation for initiation alone is not 
enough to achieve a more complete understanding of what is involved in longterm adherence to PA practice, and that including temporal aspects in the analysis, particularly the timeframe comprising adoption, adherence, dropout, lapse and return, may help in this process (Kinnafick et al. 2014).

The present study aims to analyze the explanatory variables related to return to an exercise program after interruption. The study intends to close an important gap in the literature, namely the temporal dynamics of adherence to exercise programs. The study was conducted in a fitness center in the city of Rio de Janeiro and is intended to provide researchers with further insights into the subtleties involved in long-term adherence to exercise programs. For many years, research has consistently shown that at least $50 \%$ of adults who initiate an exercise program will abandon the activity within one year of commencement (Dishman et al. 1985, Sperandei et al. 2016). What researchers have not yet looked into is what happens afterwards - do these dropouts return? If so, after how long? What variables impact on the chance of return?

\section{Methodology}

A medium-sized fitness center, with a monthly number of users ranging between 550 and 700 members, located in the central business district of the city of Rio de Janeiro, Brazil, was selected for the study. It operates between $6 \mathrm{am}$ and 10pm, Monday to Friday, and offers a variety of fitness-related equipment and facilities, such as resistance training and cardio rooms, as well as group fitness classes. Members pay a monthly fee for access to all equipment and classes offered any time of day or day of the week.

The study was exploratory and observational, using a retrospective longitudinal frame of reference. It is based on data collected by the fitness center enrollment system and includes all individuals (appropriately deidentified) who enrolled between January 2005 and June 2014. It comprises demographic information as well as details of the initial physical and motivational assessment (i.e. reasons for joining) completed within the first week of membership. Given data was collected from, and included, all enrolled individuals, there is no potential source of bias in the selection or participation criteria for this study. All database entries were used, with no missing data being present.

Only individuals who registered for the first time in this period were included in the sample. Additionally, only the first dropout and re-enrolling process was considered in the analysis. The interruption of monthly payment records was used as indicative that a dropout occurred, and the re-start of payments was considered as re-enrollment. All temporal analyses were measured in months. Each individual was monitored for 12 months or until reenrollment, whichever occurred first. The time during which the individual remained away from the fitness center was considered, regardless of the year or month the drop out or re-enrollment occurred. 
A total of 5242 individuals, with a mean age of $31.1 \pm 8.23$ years, were included in the study.

The following data were selected as co-variables:

- Sex.

- Age (up to 25 years, 26-35 years and over 35 years). The division of this variable was established to create categories with representative size, avoiding spurious results associated with very small categories.

- Level of PA before commencement (inactive or active). This variable was established through self-reporting, where inactive was defined as not having engaged in any form of regular PA for at least the preceding 30 days.

- Smoking habit (smoker, former smoker or never smoked).

- Body Mass Index (BMI) (normal - up to $25 \mathrm{~kg} / \mathrm{m}^{2}$; high - above $25 \mathrm{~kg} / \mathrm{m}^{2}$ ). Height and weight were obtained by standard methods, using a mechanical Welmy $110 \mathrm{CH}$ scale.

- Motivation for practicing PA at the fitness center (weight loss, physical fitness, physical training, leisure, wellness, hypertrophy, health, musculoskeletal rehabilitation, posture and aesthetics; allowed multiple answers).

Except from height and weight, all variables were obtained by selfreporting.

The Kaplan-Meier method (Kaplan and Meier 1958) was used to establish the overall survival curve in the first step of the nonparametric analysis. Following, a series of Harrington-Fleming (Harrington and Fleming 1982) tests was performed, with the $\mathrm{r}$ parameter varying between $0,0.5$ and 1 . This procedure is equivalent to executing the log-rank, Tarone-Ware and Wilcoxon tests, respectively. Those variables with $\mathrm{P}$-value equal or less than 0.25 were included in a Cox Proportional Hazards model (Bendel and Afifi 1977). Variables that were not significant $(\mathrm{p}>0.05)$ were subsequently removed, one by one, until the most parsimonious model was obtained (Sperandei 2014). A likelihood ratio test was used to assess the significance of the final model.

\section{Results}

Table 1 presents the general characteristics and distribution of the sample according to the selected 16 variables. Following a general trend in the HCFC sector (International Health Racquet and Sportsclub Association 2018), membership of the fitness center comprised mostly women (58.8\%). Conversely, the general trend of an increasing membership rate for individuals aged 55 years and older to reach up to $25 \%$ of HCFC members worldwide (International Health Racquet and Sportsclub Association 2018, Mullen and Whaley 2010) is not evidenced in this gym, with results showing a clear predominance of the 26-35 years age group (50.1\%). Similar to findings from a 
study in the city of Pelotas (Da Silva et al. 2008), in the southern region of Brazil, the vast majority of fitness center members were non-smokers (83.3\%), a result which aligns also with previous research that suggests fitness center membership is associated with healthy behaviors (Ready et al. 2005, Schroeder et al. 2017).

Table 1. Sample Characteristics

\begin{tabular}{|c|c|c|c|c|c|}
\hline \multirow{2}{*}{\begin{tabular}{l|l} 
& \\
Variables
\end{tabular}} & \multirow[b]{2}{*}{$\mathbf{n}$} & \multirow[b]{2}{*}{$\%$} & \multicolumn{3}{|c|}{ Final Model } \\
\hline & & & $\exp ($ Coef $)$ & CI-95\% & $p$ \\
\hline \multicolumn{6}{|l|}{ Sex } \\
\hline Female & 3,081 & 58.8 & & & \\
\hline Male & 2,161 & 41.2 & & & \\
\hline \multicolumn{6}{|l|}{ Age } \\
\hline Up to 25 years & 1,399 & 26.7 & 1 & --- & --- \\
\hline 26-35 year & 2,627 & 50.1 & 1.14 & $1.02-1.27$ & 0.021 \\
\hline 36 years and older & 1,216 & 23.2 & 1.34 & $1.18-1.52$ & $<0.001$ \\
\hline \multicolumn{6}{|c|}{ Level of Physical Activity Before Joining } \\
\hline \begin{tabular}{l|l} 
Inactive \\
\end{tabular} & 3,916 & 74.7 & 1 & --- & --- \\
\hline Active & 1,326 & 25.3 & 1.34 & $1.22-1.48$ & $<0.001$ \\
\hline \multicolumn{6}{|c|}{ Length of Membership Before Dropout } \\
\hline Up to 6 months & 4,530 & 86.4 & 1 & --- & --- \\
\hline More than 6 months & 712 & 13.6 & 1.59 & $1.42-1.78$ & $<0.001$ \\
\hline \multicolumn{6}{|l|}{ Smoking Habits } \\
\hline \begin{tabular}{l|l} 
Smoker \\
\end{tabular} & 528 & 10.1 & & & \\
\hline Former Smoker & 346 & 6.6 & & & \\
\hline \begin{tabular}{l|l} 
& Non-Smoker \\
\end{tabular} & 4,368 & 83.3 & & & \\
\hline \multicolumn{6}{|l|}{ Body Mass Index } \\
\hline \begin{tabular}{l|l} 
High \\
\end{tabular} & 2,360 & 45.0 & & & \\
\hline Normal & 2,882 & 55.0 & & & \\
\hline \multicolumn{6}{|l|}{ Motivation: Weight Loss } \\
\hline \begin{tabular}{l|l} 
No \\
\end{tabular} & 1,662 & 31.7 & & & \\
\hline Yes & 3,580 & 68.3 & & & \\
\hline \multicolumn{6}{|c|}{ Motivation: Physical Fitness } \\
\hline No & 3,559 & 67.9 & & & \\
\hline Yes & 1,683 & 32.1 & & & \\
\hline \multicolumn{6}{|c|}{ Motivation: Physical Training } \\
\hline \begin{tabular}{l|l} 
No \\
\end{tabular} & 5,078 & 96.9 & & & \\
\hline Yes & 164 & 3.1 & & & \\
\hline \multicolumn{6}{|l|}{ Motivation: Leisure } \\
\hline \begin{tabular}{l|l} 
No \\
\end{tabular} & 5,179 & 98.8 & & & \\
\hline
\end{tabular}




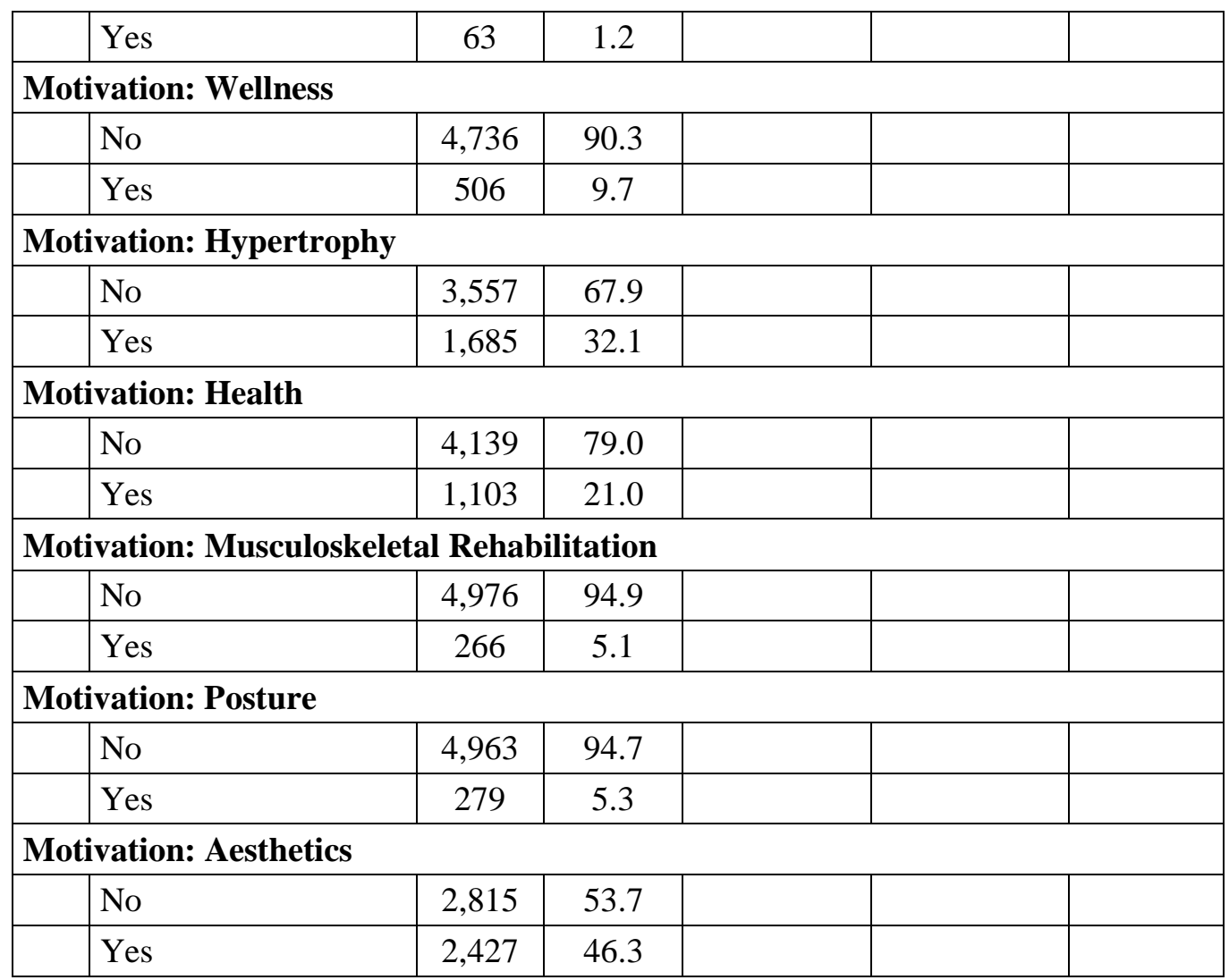

Other highlights of the sample's characteristics include a high proportion of inactive individuals before starting their activities, weight loss being the most cited motivation for enrolling in the fitness center - a finding consistent with a population study in southern Brazil (Da Silva et al. 2008) - and physical training and leisure being cited by only $3 \%$ of individuals as their motivation for joining.

The overall analysis of individuals' return to the fitness center is presented in Figure 1. Here, the cumulative returning probability is used instead of the traditional Kaplan-Meier survival curve because the event of interest (i.e. returning) is desirable, unlike the usual "death event" used in this kind of analysis. In total, only $38 \%$ of individuals who dropped out in the period of analysis returned to the fitness center within 12-months. The curve shows that the probability of an individual returning to the fitness center after an interruption of one month was 0.22 ; for a period of two months, the probability was 0.27 , and so on. In summary, the probability of an individual returning by the end of 12 months was only 38\%. Of those who return, more than half $(22 \%)$ return within the first month after cessation, which means that after the first month the probability of an individual returning is approximately only $16 \%$. 
Figure 1. Overall Probability of Returning to the Fitness Center. Dashed Lines Represent 95\% Confidence Intervals

Overall Probability of Returning to the Fitness Center

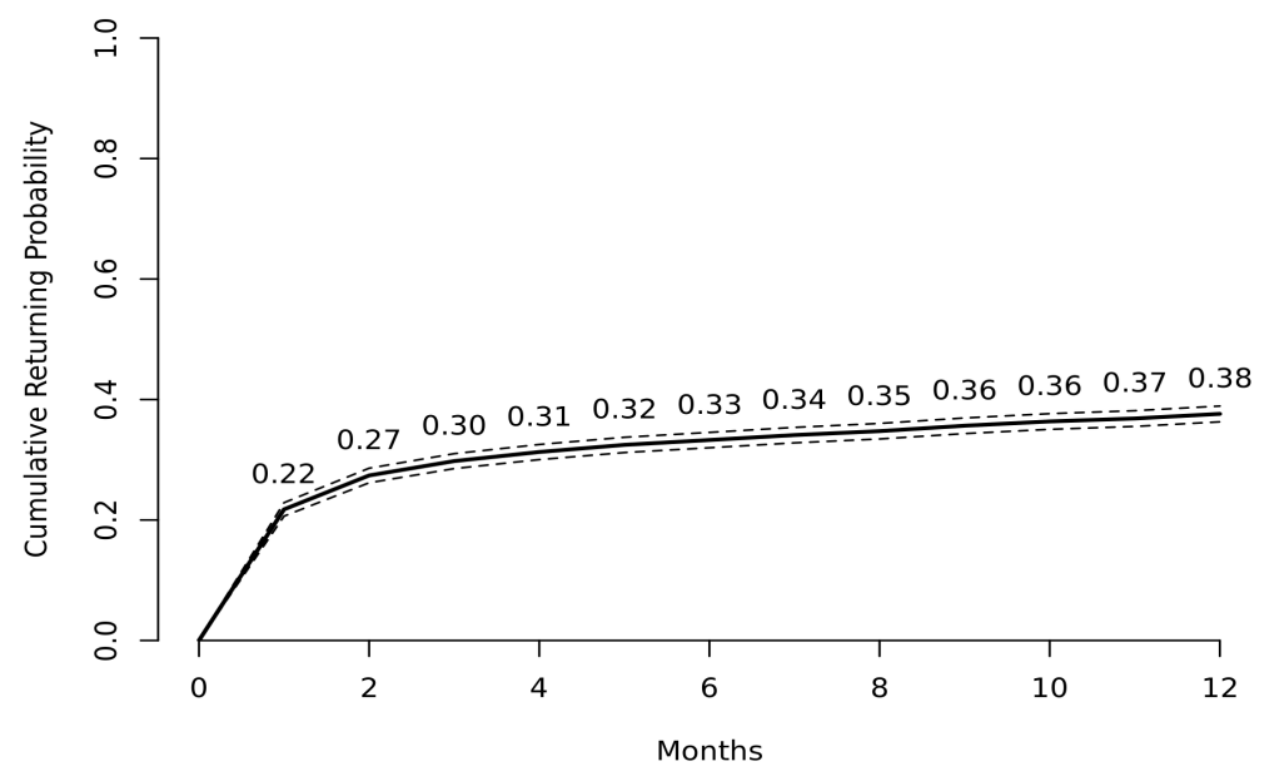

The final model fitted to these data presented the following variables as significantly related to the likelihood of an individual returning to the fitness center after dropout: age, being physically active before joining the fitness center, and length of membership before dropout. No other variable, including the motivational factors, significantly impacted on return rates.

Results show that older individuals (36 years and older) have a higher chance of returning to their exercise program after an interruption of their membership. Individuals who were inactive before starting at the fitness center have a lower chance of return. In addition, the longer the individual stays active the higher the chance of them returning to the fitness center.

A profile of representative individuals who possess the significant characteristics was created to determine the probability of return of different profiles. Figure 2 presents the estimates for the profile of the best prognosis (aged over 35 years, active, and a member for more than 6 months) and of the worst prognosis (age up to 25 years, inactive, and a member for no more than 6 months).

Figure 2 shows that less than $30 \%$ of individuals fitting the worst prognosis profile will return to the fitness center within 12 months after cessation. On the other hand, approximately $63 \%$ of those who fit the best prognosis profile are likely to return within 12 months. In addition, $41 \%$ of those who fit the best prognosis profile return within the first month after cessation, a rate considerably higher than those with the worst prognosis profile can achieve within 12 months. 
Figure 2. Probability of Returning According to Different Profiles

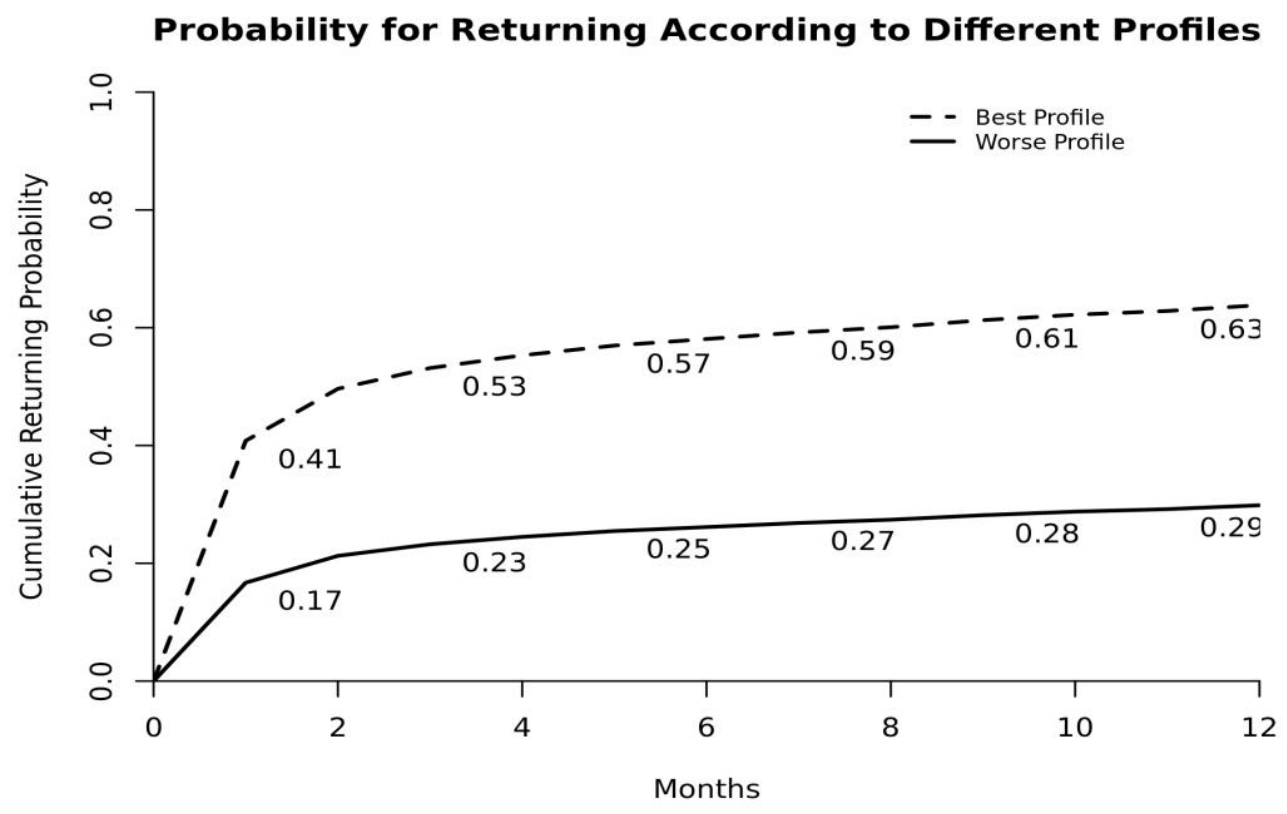

\section{Discussion}

Among the drop out group, only $38 \%$ returned to fitness center activities in a 12-month period. The majority of those $(57.9 \%)$ returned within one month. Depending on personal characteristics, the overall 12-month return rate was as low as $29 \%$ of individuals, or significantly higher, with more than $60 \%$ of individuals returning to the fitness center.

Research by the American College of Sports Medicine (2013) has found that only $5 \%$ of sedentary adults who initiate an exercise program in a HCFC setting adhere to the practice. A population study conducted in a Brazilian city found that $60.1 \%$ of individuals had been members of a HCFC in the past but only $7.8 \%$ were members at the time of the study (Da Silva et al. 2008). These numbers highlight not only low adherence rates but also point to the fact that there is a high turnover of HCFC members, a scenario that McCarthy (2007) labels as a triple loss: financially, for HCFCs owners, an opportunity loss for HCFC managers and an experiential loss for members. We add that, significantly, it is also a lost opportunity for achieving personal and public health goals.

Findings from a previous study investigating the factors contributing to dropout among this sample (Sperandei et al. 2016) found a very similar pattern to the one described above for return rates. In the former study, the best prognosis profile associated with adherence was also composed of individuals aged over 35 years and who were active before becoming a member of the fitness center, although motivational factors such as hypertrophy, health and aesthetics were also positively related to longer-term adherence, while weight loss as a motivation negatively impacted on adherence. At the other end of the 
spectrum, the worst prognosis profile associated with adherence was composed of individuals aged up to 25 years who had never engaged in PA before joining the fitness center, a similar profile to the one found here for lower likelihood of return after interruption. The combination of the two sets of findings suggests that younger and previously inactive individuals not only have a higher chance of dropping out from their exercise program, but also a lower chance of returning after an interruption. This outcome is aggravated by the fact that, given they have a higher chance of dropping out and they are likely to stay active for a shorter period of time, this will further reduce the chance of their return. It is important to highlight that this cohort represents more than one fifth $(20.5 \%)$ of the total membership, showing how significant this group is to the fitness center as a sustainable business.

Furthermore, combining the present findings with those previously published that showed that less than $5 \%$ of members stay active for more than 12 months (Sperandei et al. 2016), the present results suggest that the fitness center will lose almost all its membership within 12 months, as those who dropout are not likely to return. This means extensive resources need to be constantly invested by the business to attract new members who may never reap the benefits associated with PA, given they are likely to dropout within 3 months of commencement (Hurley 2004, Sperandei et al. 2016). Studies conducted in HCFC settings have found similar dropout rate patterns and have reported on investments made by managers to continually recruit new members (Gonçalves and Diniz 2015, Gonçalves et al. 2016, Hurley 2004). Surprisingly, however, previous research has found that only half of senior HCFC managers reported being more concerned with keeping customers than with attracting new ones (Hurley 2004), a worrying statistics that suggests a disregard by HCFC managers for the benefits their service is supposed to deliver.

Interestingly, return rates were not impacted by motivational factors for initial adherence, suggesting that once the individual drops out, the motivation to initiate in the first place becomes less relevant, emphasizing the significance of establishing a habit or routine in maintaining long-term adherence (Cañamero et al. 2019, Kinnafick et al. 2014, Neal et al. 2013, Pridgeon and Grogan 2012, Teychenne et al. 2015), even when an interruption from practice is experienced.

In addition, common barriers to PA practice identified in previous studies include lack of time, lack of enjoyment, lack of social support and, significantly for this study, lack of past exercise behavior (Trost et al. 2002). Our results show that individuals who maintain their membership for longer, and who therefore are expected to have developed a habit of exercising, are less likely to dropout and more likely to come back to activities after an interruption. Cañamero et al. (2019) highlight that individuals who attend a HCFC with the purpose of staying fit or having a healthier lifestyle were more likely to continue membership than those whose objectives were to lose weight or improve their body image. These results reinforce the importance of creating mechanisms to help individuals sustain PA practice for longer than 6 consecutive months to ensure long-term adherence to exercise practice. Our 
results emphasize also the need for $\mathrm{HCFC}$ to create strategies to re-attract quickly individuals who interrupt membership, as the longer they are away from their spaces of practice the less likely they are to return.

In regards to the association between demographic variables and the likelihood of return after an interruption in PA practice, in contrast to other studies that indicate women face more barriers to engage in PA (Cousins and Gillis 2005, Sørensen and Gill 2008), our results did not show a significant difference in return rates between males and females. Indeed, the previously published study using the same database also did not find sex to be correlated to dropout. One potential explanation for such difference is that previous studies have focused more on adoption and adherence than on dropout, lapse and return (Kinnafick et al. 2014), which, this study suggests, may present differing patterns. Also, given that HCFCs tend to attract more women than men, as industry data confirms (International Health Racquet and Sportsclub Association 2018), it might be a setting that not only presents more appeal to this group but also offers services that support adoption and adherence, such as childcare facilities, for instance. It is an issue, however, that deserves further investigation.

It is important to note that this study did not explore the reasons for drop out/interruption, or the motivation to return, although we have taken into account the initial motivation to join the fitness center. Gjestvang et al. (2019) found that, in a population of $125 \mathrm{HCFC}$ members in Europe, $44.2 \%$ reported dropping out from the previous HCFC due to lack of motivation, which the authors suggested could be explained by little to no change in physical fitness, body composition and weight. A report by IHRSA suggested that almost $30 \%$ of former HCFC members intend to join another similar establishment within 12 months of discontinuing membership with their former club (Hurley 2004), although there is no confirmation that this intention will translate into actual behavior. In addition, marketing research at HCFCs has suggested that satisfaction with service delivery, among other service-related variables, affect membership (Ferrand et al. 2010, Gonçalves et al. 2016, Hurley 2004), implying that members might leave a fitness center to move to another one, and therefore continue their practice, as IHRSA's report suggests. It is recommended, therefore, that future research should explore these temporal dynamics now incorporating information on subsequent movement of members to other HCFCs or other PA practices and settings to confirm if these dropout rates reflect only a short interruption in practice or long term cessation.

Other important limitations of the present study are that data on frequency of attendance were not recorded and that monthly payment of fitness center fees was used as the measure of adherence. In regards to the former, research has consistently shown a correlation between frequency of participation and adherence to PA practice (Clavel San Emeterio et al. 2019, Ferrand et al. 2010, Garay et al. 2014, Tsitskari et al. 2014). However, a study conducted in a fitness center in Portugal found that weekly frequency of attendance did not predict retention (Gonçalves et al. 2016), emphasizing the need for further work in this field. Regarding the latter, although it is possible that individual 
members make payments for one or more months but not attend the fitness center before cancelling their membership, we assume that not a considerable number will do so, being negligible in a sample of more than 5000 individuals. If that is the case, however, it only provides further evidence of lack of continued engagement in an exercise program, making our results even more alarming.

Overall, although data presented here were obtained from only one fitness center, similar results from a similar study (Garay et al. 2014) conducted in a different fitness center in Brazil confirm findings. The results also align with general predictions found in the international literature reviewed above. Even though some probabilities and percentages may vary from one fitness center to another, the robustness of the data presented here suggests that the profiles described above will be consistent across locations and should be taken into consideration by managers and trainers. Nonetheless, given the paucity of research investigating the temporal dynamics associated with adherence, dropout, lapse and return to exercise programs in unsupervised settings, it is recommended that more studies in this field be conducted to further corroborate our findings.

\section{Conclusion}

In this paper, we have presented data that provide a novel contribution to research in the field of adherence to PA practice. In particular, we have brought to the fore the temporal dynamics associated with adherence, dropout, lapse and return to exercise programs in the unsupervised setting of a fitness center.

A ten-year analysis involving more than five thousand individuals showed that the probability of members of a fitness center returning to activities after an interruption was less than $40 \%$. More than half of returning individuals will return in the first month after dropout. After the first month, the probability of returning is approximately $16 \%$ only. The study found that young adults, who comprise a considerable proportion of fitness center membership, are less likely to return to their activities once they dropout. This situation is aggravated by other characteristics, namely level of prior PA engagement and length of membership of the fitness center. In addition, this study found also that the profile of those less likely to return was very similar to that of those more likely to dropout, as presented in previous work using the same dataset (Sperandei et al. 2016). It is therefore very important that PA professionals and managers working in HCFC settings pay especial attention to those presenting the characteristics described here and develop strategies to prevent, first, the dropout and, second, to achieve a swift return, given that the probability of returning after the first month's absence is very low. 


\section{Acknowledgements}

The first author is the recipient of a postdoctoral scholarship from Fundação de Amparo à Pesquisa do Estado do Rio de Janeiro (FAPERJ) and Coordenação de Aperfeiçoamento de Pessoal de Nível Superior (CAPES).

\section{References}

American College of Sports Medicine (2013) ACSM's Guidelines for Exercise Testing and Prescription. Philadelphia: Lippincott Williams \& Wilkins.

Bendel RB, Afifi AA (1977) Comparison of stopping rules in forward "stepwise" regression. Journal of the American Statistical Association 72(357): 46-53.

Berry TR, Rodgers WM, Divine A, Hall C (2018). The relationship of explici-implicit evaluative discrepancy to exercise dropout in middle-aged adults. Journal of Sport \& Exercise Psychology 40(2): 92-100.

Biddle SJ, Mutrie N (2007) Psychology of Physical Activity: Determinants, Well-Being and Interventions. London: Routledge.

Cañamero SR, García-Unanue J, Luis Felipe J, Sánchez-Sánchez J, Gallardo L (2019) Why do clients enrol and continue at sports centres? Sport, Business and Management: An International Journal. Epub ahead of print 14 April 2019. DOI: 10.1108/SBM-10-2018-0077.

Clavel San Emeterio I, García-Unanue J, Iglesias-Soler E, Luis Felipe J, Gallardo L (2019) Prediction of abandonment in Spanish fitness centres. European Journal of Sport Science 19(2): 217-224.

Costa BVd, Bottcher LB, Kokubun E (2009) Aderência a um programa de atividade física e fatores associados. Motriz: Revista de Educação Física 15(1): 25-36.

Courneya KS, Karvinen KH, McNeely ML, Campbell KL, Brar S, Woolcott CG, McTiernan A, Ballard-Barbash R, Friedenreich CM (2012) Predictors of Adherence to Supervised and Unsupervised Exercise in the Alberta Physical Activity and Breast Cancer Prevention Trial. Journal of Physical Activity and Health 9(6): 857-866.

Cousins SOB, Gillis MM (2005) "Just do it... before you talk yourself out of it": the self-talk of adults thinking about physical activity. Psychology of Sport and Exercise 6(3): 313-334.

Da Silva MC, Rombaldi AJ, Azevedo MR, Hallal PC (2008) Participação atual e passada em academias de ginástica entre adultos: prevalência e fatores associados. [Current and past participation in gyms among adults: prevalence and associated factors]. Revista Brasileira de Atividade Física \& Saúde 13(1): 28-36.

Dishman RK, Sallis JF, Orenstein DR (1985) The determinants of physical activity and exercise. Public Health Reports 100(2): 158-171.

Ferrand A, Robinson L, Valette-Florence P (2010) The intention-to-repurchase paradox: A case of the health and fitness industry. Journal of Sport Management 24(1): 83-105.

Jones F, Harris P, Waller H, Coggines A (2005) Adherence to an exercise prescription scheme: The role of expectations, self-efficacy, stage of change and psychological well-being. British Journal of Health Psychology 10(3): 359-378.

Garay LC, Sperandei S, Palma A (2014) O impacto das características individuais na permanência em programas de atividades físicas numa academia de ginástica. [The impact of individual characteristics on staying in programs of physical activities in a gym]. Motricidade 10(3): 3-11. 
Gjestvang C, Stensrud T, Haakstad LAH (2019) Are changes in physical fitness, body composition and weight associated with exercise attendance and dropout among fitness club members? Longitudinal prospective study. BMJ Open. Epub ahead of print 14 April 2019. DOI: 10.1136/bmjopen-2018-027987.

Gonçalves C, Diniz A (2015) Analysis of member retention in fitness through satisfaction, attributes perception, expectations and well-being. Revista Portuguesa de Marketing 38(34): 65-76.

Gonçalves C, Meireles P, Carvalho MJ (2016) Consumer behaviour in Fitness Club: study of the weekly frequency of use, expectations, satisfaction and retention. The Open Sports Sciences Journal 9(1): 1-9.

Hanlon C, Morris T, Nabbs S (2014) Program providers' perspective: Recruitment and retention strategies for women in physical activity programs. Sport Management Review 17(2): 133-144.

Harrington DP, Fleming TR (1982) A class of rank test procedures for censored survival data. Biometrika 69(3): 553-566.

Hooker SA, Ross KM, Ranby KW, Masters KS, Peters JC, Hill JO (2016) Identifying groups at risk for 1-year membership termination from a fitness center at enrollment. Preventive Medicine Reports 4: 563-568.

Hurley T (2004) Managing customer retention in the health and fitness industry: a case of neglect. Irish Marketing Review 17(1/2): 23-29.

International Health Racquet and Sportsclub Association (2018) Global Report 2018. Boston: IHRSA.

Kaplan EL, Meier P (1958) Nonparametric estimation from incomplete observations. Journal of the American Statistical Association 53(282): 457-481.

Kinnafick FE, Thøgersen-Ntoumani C, Duda JL (2014) Physical Activity Adoption to Adherence, Lapse, and Dropout:A Self-Determination Theory Perspective. Qualitative Health Research 24(5): 706-718.

Kubo K, Ikebukuro T, Yata H, Tsunoda N, Kanehisa H (2010) Time Course of Changes in Muscle and Tendon Properties During Strength Training and Detraining. The Journal of Strength \& Conditioning Research 24(2): 322-331.

Kuehl R, Schmidt ME, Dreger P, Steindorf K, Bohus M, Wiskemann J (2016) Determinants of exercise adherence and contamination in a randomized controlled trial in cancer patients during and after allogeneic HCT. Supportive Care in Cancer 24(10): 4327-4337.

Lorenz EC, Amer H, Dean PG, Stegall MD, Cosio FG, Cheville AL (2015) Adherence to a pedometer-based physical activity intervention following kidney transplant and impact on metabolic parameters. Clinical Transplantation 29(6): 560-568.

Masuki S, Mori M, Tabara Y, Sakurai A, Hashimoto S, Morikawa M, Miyagawa K, Sumiyoshi E, Miki T, Nose H (2015) The factors affecting adherence to a longterm interval walking training program in middle-aged and older people. Journal of Applied Physiology 118(5): 595-603.

McCarthy J (2007) IHRSAS Guide to Membership Retention. Boston: IHRSA.

McNeill LH, Kreuter MW, Subramanian S (2006) Social environment and physical activity: a review of concepts and evidence. Social Science \& Medicine 63(4): 1011-1022.

Mullen SP, Whaley DE (2010) Age, gender, and fitness club membership: Factors related to initial involvement and sustained participation. International Journal of Sport and Exercise Psychology 8(1): 24-35. 
Neal DT, Wood W, Drolet A (2013) How do people adhere to goals when willpower is low? The profits (and pitfalls) of strong habits. Journal of Personality and Social Psychology 104(6): 959-975.

Pridgeon L, Grogan S (2012) Understanding exercise adherence and dropout: an interpretative phenomenological analysis of men and women's accounts of gym attendance and non-attendance. Qualitative Research in Sport, Exercise and Health 4(3): 382-399.

Ready A, Naimark B, Tate R, Boreskie S (2005) Fitness centre membership is related to healthy behaviours. Journal of Sports Medicine and Physical Fitness 45(2): 199-207.

Schroeder EC, Welk GJ, Franke WD, Lee D (2017). Associations of health club membership with physical activity and cardiovascular health. PlosOne 12(1): e0170471.

Smith RA, Biddle SJH (1999) Attitudes and exercise adherence: Test of the Theories of Reasoned Action and Planned Behaviour. Journal of Sports Sciences 17(4): 269-281.

Sørensen M, Gill DL (2008) Perceived barriers to physical activity across Norwegian adult age groups, gender and stages of change. Scandinavian Journal of Medicine \& Science in Sports 18(5) 651-663.

Sperandei S (2014) Understanding logistic regression analysis. Biochemia Medica 24(1): 12-18.

Sperandei S, Vieira MC, Reis AC (2016) Adherence to physical activity in an unsupervised setting: Explanatory variables for high attrition rates among fitness center members. Journal of Science and Medicine in Sport 19(11): 916-920.

Teychenne M, Ball K, Salmon J, Daly RM, Crawford DA, Sethi P, Jorna M, Dunstan DW (2015) Adoption and maintenance of gym-based strength training in the community setting in adults with excess weight or type 2 diabetes: a randomized controlled trial. International Journal of Behavioral Nutrition and Physical Activity 12(1): 105.

Titze S, Stronegger W, Owen N (2005) Prospective study of individual, social, and environmental predictors of physical activity: women's leisure running. Psychology of Sport and Exercise 6(3): 363-376.

Trost SG, Owen N, Bauman AE, Sallis JF, Brown W (2002) Correlates of adults' participation in physical activity: review and update. Medicine \& Science in Sports \& Exercise 34(12): 1996-2001.

Tsitskari E, Quick S, Tsakiraki A (2014) Measuring exercise involvement among fitness centers' members: is it related with their satisfaction? Services Marketing Quarterly 35(4): 372-389.

Vieira MC, Sperandei S, Reis A, da Silva CGT (2013) An analysis of the suitability of public spaces to physical activity practice in Rio de Janeiro, Brazil. Preventive Medicine 57(3): 198-200.

Viljoen JE, Christie CJA (2015) The change in motivating factors influencing commencement, adherence and retention to a supervised resistance training programme in previously sedentary post-menopausal women: a prospective cohort study. BMC Public Health 15(1): 236.

Vlachopoulos S, Neikou E (2007) A prospective study of the relationships of autonomy, competence, and relatedness with exercise attendance, adherence, and dropout. Journal of Sports Medicine and Physical Fitness 47(4): 475-482. 